\title{
Health-Related Quality of Life in Adults Over 45 Years: A Cross Sectional Study from Istanbul
}

\author{
Suphi Vehid ${ }^{1 \oplus}$, Abdülhamit Enes Camcıoğlu ${ }^{2 \oplus}$, Uğurcan Sayılı ${ }^{2 \oplus}$, Esin Çetinkaya Sümer ${ }^{3 \oplus}$, \\ Sıdıka İpek Akdeniz ${ }^{2 \oplus}$, Ethem Erginö $z^{4 \oplus}$, Eray Yurtseven ${ }^{5 \odot}$
}

DOI: $10.26650 / F N J N 402258$

${ }^{1} \mathrm{MD}$, PhD. Prof., Istanbul Bilim University, Faculty of Medicine, Department of Public Health, Istanbul, Turkey

${ }^{2} \mathrm{MD},{ }^{4} \mathrm{MD}$, PhD. Prof., ${ }^{5} \mathrm{PhD}$. Assoc. Prof., Istanbul University, Cerrahpasa Faculty of Medicine, Department of Public Health, Istanbul, Turkey

${ }^{3}$ MD, Bakirkoy Prof. Mazhar Osman Psychiatric and Neurological Illnesss Training and Investigation Hospital, Istanbul, Turkey

Sorumlu yazar/Corresponding author: Suphi Vehid,

Istanbul Bilim University, Faculty of Medicine Department of Public Health, Istanbul, Turkey Telefon/Phone: +90212 213 6483/152

E-posta/E-mail: suphi.vehid@gmail.com

Geliş tarihi/Date of receipt: 06.03.2018 Kabul tarihi/Date of acceptance: 29.06.2018

Atıf/Citation: Vehid, S., Camcıoğlu, A. E., Sayıll, U., Çetinkaya-Sümer, E., Akdeniz, S. İ., Erginöz, E. ve Yurtseven, E. (2018). Health-related quality of life in adults over 45 years: A cross sectional study from Istanbul. FNJN Florence Nightingale Journal of Nursing, 26(3), 149-157. https://doi.org/10.26650/FNJN402258

\section{ABSTRACT}

Aim: In this study, we aimed to measure the quality of life of adults over 45 years old living in Silivri district of Istanbul and to show the relation with sociodemographic factors.

Method: In this cross-sectional study, we collected the data from people over 45 years who live in Silivri district. In our study questions on demographic status were asked beside the 36 questions existing in the SF 36 forms.

Results: A total of 705 individuals were interviewed: 597 males and 108 females, the mean age of $60.36 \pm 11.77$ years. The physical function found to be statistically different was according to age we determined that there are statistically significant differences between males and females according to the scores of the health quality of life parameters $(p<0.05)$. There was a significant difference present on bodily pain and physical function among the variables of quality of life according to the BMI classification $(p<0.05)$.

Conclusion: According to the results of our study, females living in Silivri district have significantly lower scores of the variables of SF 36 .

Keywords: Quality of life, health status, SF-36 health survey 


\section{INTRODUCTION}

The rapid increase in the length of life is one of the most important reasons for the increased prevalence of noncommunicable disease in the elderly (Barros, César, Carandina, \& Torre, 2006). Despite the increase in noncommunicable diseases, the health of the elderly population can be kept at a good level and they can remain in a position to maintain their basic needs, their role in society and their earnings (Ramos, 2003). For these reasons, it is one of the biggest problems of public health to enhance the number of years in which the elderly are living healthy (Lima et al., 2009).

The promotion of health is a process that aims to control and foster human health. It doesn't focus on individual act, but it moves towards a large spectrum of social and environmental interventions (WHO, 2018).

One of the ways of promoting health is to increase the quality of life. The assessment of status is always at the very front on the way to planning a better quality of life (Mallmann, Galindo Neto, Sousa, \& Vasconcelos, 2015).

There are some demographic factors that can effect both the promotion of health and the quality of life, such as education, age and gender. On the other hand, chronic illnesses and obesity are among the factors - other than demographic factors - which affect health. There are numerous articles interested in the relationship between chronic diseases and the quality of life (Van Son, De Vries, Roukema, \& Den Oudsten, 2013).

Obesity is a public health problem with enhancing prevalence and is one of the important causes of high morbidity and mortality in chronic diseases. In many cross-sectional studies, obesity has been shown to be associated with impairment in physical functions, one of the indicators of health-related quality of life (Frank, Andresen, \& Schmid, 2004).

Gender and age are the permanent factors which can influence health status and the quality of life. It has become especially important today to determine the age related health problems among the young population and aged population, in particular in connection with the transformation of the demographic structures of communities into samples of aged populations. Studies carried out in Canada and Sweden report that the decrease of the SF 36 is in line with the increase of age among males (Pinar, 2005). Turkey is a country where the population is rapidly aging. The median age was 19.9 in Turkey in 1980 (Yakar, 2014); according to TÜiK data, the median age rose to 31.7 in 2017 (Türkiye İstatistik Kurumu Başkanlığı, 2018b). The median age for population projections made in Turkey predicts that the median age will rise to 33.5 in 2023; to 38.5 in 2040; It is predicted that in 2080 it will be 45 years (Türkiye İstatistik Kurumu Başkanlığı, 2018c). The percentage of people over 45 has reached 29.6\% within the population in 2017 (Türkiye İstatistik Kurumu Başkanlığı, 2018a). Decreased quality of life and deterioration in health status can be expected due to increasing median age in our country.

In this study, we aimed to measure the quality of life of adults over 45 years old living in Silivri district of Istanbul and to show the relation with sociodemographic factors.

For this purpose, we performed a Turkish version of SF -36 in our study to the people living in the neighbourhoods of the Silivri district. We also attempted to determine the relationship between age, gender, education, BMI and chronic illnesses and the quality of life of a population living in the rural and semi-rural settlement areas of Istanbul.

\section{METHOD}

\section{Study Design}

It is a cross-sectional study.

\section{Sample}

The population of the study consisted of 25,331 adults over 45 years of age living in Silivri. The study was conducted within the scope of internship education (Grade 6 Program, Medicine Faculty). In 
one year, the accessible part of the study population was tried to be reached. For this reason, a sample size calculation was not made.

\section{Data Collection}

The questionnaires were made with a face-to-face interview at public places, family medicine centers, local authority service units, etc. The questionnaire was applied to 705 of the total. Our study population represented $3 \%$ of the total. This was mentioned as a limitation. In our study we aimed to meet people outside their homes instead of visiting them in their homes. This explains the reason why we have more males in the study.

This study was started in January 2016 after obtaining the necessary permissions and lasted until December 2016. We tried to meet people over the age of 45 by obtaining their data from the mukhtars (headmen) of the neighbourhoods of the Silivri district.

In our study questions on demographic status were asked beside the 36 questions existing in the SF 36 forms. The Short Form-36 Health Survey (SF-36) makes it possible to measure the quality of life of a population and make comparisons between different populations. The scale was developed by Ware (Ware Jr \& Sherbourne, 1992). The Short Form-36 Health Survey (SF-36) is an eight-dimensional measurement of various health parameters (Ware JE \& Gandek, 2014). SF-36 does research about health-related quality of life including role-physical, physical function, physical pain, general health, vitality, roleemotional, social functioning and mental health dimensions. It has a general utility for measuring health concepts related to functional capacity and well-being of all. This general measure can also be practised in a population with any disease, such as in general populations. SF-36 is also a suitable measure for comparing various disease groups, such as lung and stomach cancer patients. SF-36 has been reported as useful in clinical practice, research, health policy evaluations, and population surveys (Brown et al.,
2000; Ware JE \& Gandek, 2014). Ten of the questions were related to Physical Functions, five of them were related to Mental Health and General Health, four of them were related to Physical role restriction and vitality, 3 were related to Emotional role restrictions and two were related to restrictions on social functions and feeling pain. The remaining one was related to health status for more than a year. The questions were collected together under 8 subtitles. The validation and reliability studies of the Turkish version of SF-36 were carried out in patient groups in 1999, making it possible to carry out studies on the Turkish population. For each subscale of the scale, the Cronbachs alpha coefficient ranged from 0.73 to 0.76 ; item-total score correlations were also found to be significant (Kocyigit, 1999).

The participants gave appropriate answers for the questions in the SF-36 scale. Scores changed from 0 to 100 for each domain separately. "0" indicates the worst health quality and "100" indicates the best health quality.

\section{Data Analyses}

Statistical analyses were performed using the SPSS version 15.0. Descriptive analyzes were shown as mean \pm standard deviation or in frequencies (n) and percentages (\%). Chi-square test was used to compare the differences in proportions of categorical variables between groups. The normal distribution of the data was tested by the normality test (Kolmogorov Smirnof Test). Student $t$ test and Kruskall-Wallis Test were used for comparison of quantitative variables. Mean and standard deviation were estimated for the Health level points. The median of health level points were accepted as a cut-off point and logistic regression analyses were applied to each health condition separately. We tried to estimate the Odds Ratios of the Gender, BMI, age, education and any existing disease as an independent variable. Logistic regression analysis was used to determine the factors affecting SF-36 test variables. A value of $p<0.05$ was accepted to be statistically significant. 


\section{Ethical Considerations}

This study was permitted by the Ethical Committee of the Cerrahpasa Faculty of Medicine and the study was conducted with respect to the principles of the Declaration of Helsinki. Informed consent was obtained from participants.

\section{RESULTS}

A total of 705 individuals were interviewed: 597 men and 108 women, with a mean age of $60.36 \pm 11.77$ years. Most of the participants were in the 45 to 64 age group (63.2\%). (Table 1) There is no significant distribution differences between the age groups according to gender $(p=0.243)$.

Age: The physical function found to be statistically different was according to age. Participants younger than the age of 65 have a higher mean score than participants older than 65. (Table 2) As seen from Table 3, we found that people older than 65 are under
2.5 times more risk than people younger 65, according to physical functions. On the other hand, Mental Health score of the participant found significantly different according to the age of the participants where older than the age of 65 have higher mean score than participants younger than 65 (Table 2).

Gender: In our study, apart from mental health scores, we determined that there are statistically significant differences between males and females according to the scores of the health quality of life parameters. According to our results it is possible to say males have higher health quality scores than females (Table 2).

Health Status: People determined as healthy differ from the people determined to be unhealthy according to their average scores of quality of life variables, apart from Mental Health (Table 2). People with any chronic diseases influences feel pain 2.3 times more than people with no chronic diseases (Table 3).

Table 1. Gender comparison of demographic variables for each age group

\begin{tabular}{|c|c|c|c|c|c|c|}
\hline \multirow{2}{*}{ Variable } & \multicolumn{3}{|c|}{ Aged 45 to 64 Years } & \multicolumn{3}{|c|}{ Aged $>65$ Years } \\
\hline & Female $(n=74)$ & Male $(n=374)$ & Statistics & Female $(n=34)$ & Male $(n=223)$ & Statistics \\
\hline \multicolumn{7}{|l|}{ Marital Status } \\
\hline Single & 4 & 14 & $\chi^{2}=16.754$ & 0 & 3 & $\chi^{2}=12.781$ \\
\hline Married & 59 & 347 & $d f=3$ & 24 & 192 & $d f=3$ \\
\hline Divorced & 3 & 4 & $p=0.001$ & 0 & 8 & $p=0.005$ \\
\hline Widowed & 8 & 6 & & 10 & 20 & \\
\hline \multicolumn{7}{|l|}{ Educational Level } \\
\hline No formal education & 8 & 18 & $\chi^{2}=5.40$ & 6 & 16 & $\chi^{2}=3.213$ \\
\hline Primary - Elementary & 59 & 300 & $d f=3$ & 27 & 186 & $d f=3$ \\
\hline High school & 6 & 34 & $p=0.144$ & 1 & 8 & $p=0.360$ \\
\hline University & 1 & 17 & & 0 & 7 & \\
\hline Missing & 0 & 5 & & 0 & 6 & \\
\hline \multicolumn{7}{|l|}{ Disease existing } \\
\hline No & 17 & 212 & $\chi^{2}=5.40$ & 26 & 137 & $\chi^{2}=2.875$ \\
\hline Yes & 57 & 162 & $\begin{array}{c}d f=1 \\
p<0.001\end{array}$ & 8 & 86 & $\begin{array}{c}d f=1 \\
p=0.064\end{array}$ \\
\hline \multicolumn{7}{|l|}{ BMI } \\
\hline $15-20$ & 1 & 4 & $\chi^{2}=23.55$ & 0 & 6 & $\chi^{2}=17.43$ \\
\hline $20-25$ & 8 & 93 & $d f=5$ & 1 & 59 & $d f=5$ \\
\hline $25-30$ & 25 & 122 & $p<0.001$ & 6 & 72 & $p=0.004$ \\
\hline $30-35$ & 17 & 71 & & 9 & 35 & \\
\hline $35-40$ & 7 & 17 & & 2 & 6 & \\
\hline $40-45$ & 5 & 2 & & 1 & 1 & \\
\hline Missing & 11 & 65 & & 15 & 44 & \\
\hline
\end{tabular}

Chi square test was applied. 
Table 2. Mean (SD) scores of eight variables by gender, age and some demographic variables in study group

\begin{tabular}{|c|c|c|c|c|c|c|c|c|}
\hline & GH & BP & Vit & $\mathrm{MH}$ & PP & PF & SF & EP \\
\hline \multicolumn{9}{|l|}{ Age* $^{*}$} \\
\hline$<65$ & $66.3 \pm 18.5$ & $83.8 \pm 21.0$ & $73.4 \pm 17.8$ & $58.9 . \pm 10.6$ & $77.8 \pm 34.5$ & $83.4 \pm 20.0$ & $81.2 \pm 16.4$ & $73.2 \pm 35.4$ \\
\hline$>65$ & $66.3 \pm 18.9$ & $81.4 \pm 23.2$ & $72.6 \pm 17.4$ & $61.0 \pm 11.1$ & $74.0 \pm 39.2$ & $72.1 \pm 22.9$ & $81.6 \pm 16.7$ & $73.4 \pm 33.0$ \\
\hline$p$ value & 0.471 & 0.138 & 0.586 & 0.019 & 0.185 & $<0.001$ & 0.781 & 0.930 \\
\hline \multicolumn{9}{|l|}{ Gender* } \\
\hline Male & $67.1 \pm 18.1$ & $85.2 \pm 20.0$ & $73.8 \pm 17.0$ & $59.4 \pm 10.8$ & $78.3 \pm 35.1$ & $81.4 \pm 20.3$ & $82.4 \pm 15.9$ & $74.9 \pm 33.2$ \\
\hline Female & $57.8 \pm 19.8$ & $69.8 \pm 27.0$ & $66.7 \pm 20.6$ & $61.3 \pm 10.0$ & $65.5 \pm 42.1$ & $65.8 \pm 25.3$ & $72.5 \pm 19.8$ & $69.9 \pm 39.4$ \\
\hline$p$ value & $<0.001$ & $<0.001$ & 0.001 & 0.107 & 0.001 & $<0.001$ & $<0.001$ & 0.007 \\
\hline \multicolumn{9}{|l|}{ Health Status* } \\
\hline Healthy & $71.8 \pm 16.8$ & $89.2 \pm 17.2$ & $77.1 \pm 15.1$ & $59.7 \pm 10.3$ & $82.1 \pm 32.3$ & $86.7 \pm 17.6$ & $83.7 \pm 15.5$ & $77.4 \pm 32.6$ \\
\hline Unhealthy & $60.5 \pm 18.7$ & $77.4 \pm 24.1$ & $69.0 \pm 19.1$ & $59.8 \pm 11.1$ & $71.3 \pm 39.2$ & $72.3 \pm 23.0$ & $78.4 \pm 17.8$ & $69.6 \pm 35.7$ \\
\hline p value & $<0.001$ & $<0.001$ & $<0.001$ & 0.988 & $<0.001$ & $<0.001$ & $<0.001$ & 0.002 \\
\hline \multicolumn{9}{|l|}{ Marital Situation* } \\
\hline Never married & $60.4 \pm 21.8$ & $75.5 \pm 24.8$ & $66.1 \pm 21.7$ & $61.6 \pm 12.1$ & $65.5 \pm 41.1$ & $68.6 \pm 25.0$ & $71.8 \pm 22.7$ & $57.2 \pm 40.6$ \\
\hline Married & $66.3 \pm 18.2$ & $83.6 \pm 21.5$ & $73.5 \pm 17.1$ & $59.5 \pm 10.5$ & $77.6 \pm 35.8$ & $80.2 \pm 21.2$ & $82.0 \pm 15.6$ & $75.2 \pm 33.1$ \\
\hline p value & 0.02 & 0.002 & 0.003 & 0.04 & 0.005 & $<0.001$ & $<0.001$ & $<0.001$ \\
\hline \multicolumn{9}{|l|}{ BMI** } \\
\hline $15-20$ & $59.4 \pm 19.6$ & $98.2 \pm 4.0$ & $72.7 \pm 22.4$ & $61.1 \pm 17.2$ & $95.6 \pm 15.1$ & $82.7 \pm 18.2$ & $81.8 \pm 16.0$ & $84.9 \pm 34.1$ \\
\hline $20-25$ & $66.7 \pm 18.6$ & $86.9 \pm 18.4$ & $72.1 \pm 18.4$ & $59.1 \pm 10.5$ & $78.7 \pm 34.1$ & $83.4 \pm 18.0$ & $81.2 \pm 16.9$ & $75.7 \pm 31.9$ \\
\hline $25-30$ & $67.0 \pm 18.4$ & $82.7 \pm 22.1$ & $73.8 \pm 16.6$ & $59.6 \pm 10.7$ & $77.4 \pm 36.3$ & $80.2 \pm 21.3$ & $81.6 \pm 16.6$ & $73.9 \pm 36.1$ \\
\hline $30-35$ & $67.3 \pm 17.5$ & $82.0 \pm 22.0$ & $74.5 \pm 15.3$ & $60.6 \pm 10.3$ & $79.89 \pm 34.3$ & $80.1 \pm 20.1$ & $82.6 \pm 14.9$ & $73.0 \pm 35.3$ \\
\hline $35-40$ & $60.8 \pm 19.1$ & $77.2 \pm 22.8$ & $70.6 \pm 19.1$ & $60.0 \pm 9.8$ & $71.9 \pm 40.0$ & $70.0 \pm 25.7$ & $77.5 \pm 18.1$ & $78.1 \pm 34.5$ \\
\hline $\mathrm{p}$ value & 0.37 & 0.016 & 0.95 & 0.75 & 0.27 & 0.029 & 0.84 & 0.41 \\
\hline \multicolumn{9}{|l|}{ Education Level** } \\
\hline No formal education & $61.4 \pm 19.2$ & $74.3 \pm 25.0$ & $68.7 \pm 14.5$ & $58.7 \pm 13.3$ & $65.2 \pm 44.4$ & $65.7 \pm 26.4$ & $72.9 \pm 21.8$ & $61.5 \pm 43.4$ \\
\hline Primary - Elementary & $65.1 \pm 18.4$ & $82.9 \pm 22.0$ & $72.5 \pm 18.0$ & $60.2 \pm 10.1$ & $77.0 \pm 36.1$ & $78.9 \pm 21.6$ & $81.3 \pm 16.1$ & $74.3 \pm 33.5$ \\
\hline High school & $72.9 \pm 19.2$ & $89.6 \pm 17.8$ & $76.1 \pm 20.5$ & $56.5 \pm 11.9$ & $78.8 \pm 35.8$ & $88.0 \pm 19.0$ & $80.4 \pm 21.3$ & $70.5 \pm 36.8$ \\
\hline University & $67.9 \pm 21.0$ & $84.6 \pm 21.0$ & $74.8 \pm 17.5$ & $59.4 \pm 13.3$ & $79.8 \pm 31.6$ & $82.3 \pm 18.2$ & $82.3 \pm 15.0$ & $77.0 \pm 29.5$ \\
\hline$p$ value & 0.01 & 0.005 & 0.051 & 0.18 & $0 . \overline{3} 6$ & $<0.001$ & 0.08 & 0.35 \\
\hline
\end{tabular}

(*) Student $t$ test was applied. $\left.{ }^{* *}\right)$ Kruskall Wallis One 1-way Anova test was applied.

Abbrevetions: GH: General Health, BP: Bodily Pain, Vit: Vitality, MH: Mental Health, PP: Physical Problems, PF: Physical Functions, SF: Social Functions,

EP: Emotional Functions, BMI: Body Mass Index

Table 3. Results of the multiple regression (binary logistic) analyses of factors affecting the variables of SF-36

\begin{tabular}{|c|c|c|c|c|}
\hline & OR & Sig & 95\% Cl (lower) & 95\% Cl (Upper) \\
\hline \multicolumn{5}{|l|}{ General Health } \\
\hline Healthy (Ref healthy) & 2.474 & $<0.001$ & 1.716 & 3.566 \\
\hline \multicolumn{5}{|l|}{ Bodily Pain } \\
\hline Gender (Ref male) & 2.420 & 0.001 & 1.417 & 4.133 \\
\hline Healthy (Ref healthy) & 2.332 & $<0.001$ & 1.604 & 3.390 \\
\hline \multicolumn{5}{|l|}{ Vitality } \\
\hline Healthy (Ref healthy) & 1.841 & 0.001 & 1.284 & 2.641 \\
\hline \multicolumn{5}{|l|}{ Physical Problems } \\
\hline Gender (Ref male) & 1.805 & 0.026 & 1.073 & 3.037 \\
\hline \multicolumn{5}{|l|}{ Physical Functions } \\
\hline Gender (Ref male) & 3.171 & $<0.001$ & 1.797 & 5.597 \\
\hline Age (ref young age) & 2.495 & $<0.001$ & 1.673 & 3.722 \\
\hline Healthy (Ref healthy) & 2.460 & $<0.001$ & 1.681 & 3.600 \\
\hline \multicolumn{5}{|l|}{ Social Functions } \\
\hline Gender (Ref male) & 2.236 & 0.002 & 1.372 & 4.060 \\
\hline Healthy (Ref healthy) & 1.618 & 0.024 & 1.067 & 2.453 \\
\hline Marital status (Ref married) & 2.790 & 0.001 & 1.560 & 4.958 \\
\hline \multicolumn{5}{|l|}{ Emotional Problems } \\
\hline Gender (Ref male) & 1.840 & 0.021 & 1.098 & 3.086 \\
\hline Marital status (Ref married) & 1.938 & 0.027 & 1.080 & 3.477 \\
\hline
\end{tabular}


Marital Status: Our results show that apart from mental health score, there are statistically significant differences on their mean scores of quality of life variables, according to marital status. People who are currently married or have been married at any time have higher mean scores than those who never married (Table 2). Among the variables of quality of life, the social function is estimated to be under 2.8 times more risk among those never married compared to those who have been married. Emotionally, those who have never married have 1.9 times more risk than those who have married (Table 3).

BMI: There is a significant difference present on bodily pain and physical function among the variables of quality of life according to the BMI classification. These differences come from the group where the BMI is between 35-40, with the worst mean scores (Table 2).

Education Level: Among the variables of quality of life statistically significant differences were found on $\mathrm{GH}, \mathrm{BP}, \mathrm{PF}, \mathrm{SF}$ according to the education level. According to the results of the statistically advanced examination mean scores of the people with no education differs from the people who have received primary or secondary school education (Table 2).

\section{DISCUSSION}

When we examine studies which have been conducted on the subject of the quality of life in connection with health, we find that most of these were conducted in developed countries. The numbers of studies on the subject in our country are quite low (Demiral et al., 2006), and there is no other study in the district of Silivri, which represents our population. Our study is the first study on the subject on the population of Silivri.

As stated in the section on materials and methods, the number of male participants in our study is higher. This is also seen to be the case in similar field studies. The main reason for this are the low participation rates among female individuals in studies conducted in the field. This can be evaluated as a limitation of our study.

The expected years of life for women are usually 7 years longer than men (Vlassoff, 2007). As seen from our results and the manuscripts used, women get these 7 years through with low quality of life. This is due to the morbidity associated with long-term illnesses and body aches that limit their physical and social life. On the other hand, marital status was found to have influences on social life and emotional problems as much as gender, in the same way.

The fact that pain and analgesic effect differ in men and women has attracted great attention of scientific community and clinicians especially in last decades. Vlassoff Carol has stated that gender is an important factor which determines health, both economically and biologically. In patients with rheumatoid arthritis, male patients are dispatched to the arthritis clinic much earlier than female patients. Osteoporosis and depression are largely diagnosed in females (Vlassoff, 2007).

Apart from similar results between two genders in mental health parameters, elderly women have been reported to have lower scores on physical health parameters in a study from Iran. And also, the decline in physical health has been referred to economic poverty and many problems which affect quality of life of women in the same study (Tajvar, Arab, \& Montazeri, 2008). Similarly, our results show that females have lower scores in physical health parameters but not in mental health parameters. Although women's status in social life in Turkey and Iran are not totally the same, there are many similarities. These results are not surprising when similar geographical and sociocultural characteristics are taken into consideration. There are many studies which have mentioned that males have better general health scores than females (Curcani \& Tan, 2011; Fillingim, King, Ribeiro-Dasilva, RahimWilliams, \& Riley, 2009; Kirchengast \& Haslinger, 2008; Kroenke \& Spitzer, 1998; Lima et al., 2009; Pappa, Kontodimopoulos, Papadopoulos, \& Niakas, 2009; Regitz-Zagrosek, 2012). According to our results it is possible to say that males have higher health quality scores than females. 
Rollman \& Lautenbacher (2001) reported that musculoskeletal pain was more common in females than in males. Some new studies have examined differences in gender, regardless of where the chronic musculoskeletal pain is located. In a survey of 85,052 people living in 6 different continents, the prevalence rate of long lasting pain was reported to be $45 \%$ in females and $31 \%$ in males. Also some studies have taken attention chronic musculoskeletal pain is more common in females than males (Blyth et al., 2001; Bouhassira, Lantéri-Minet, Attal, Laurent, \& Touboul, 2008; Rustøen et al., 2004).

Several studies of prevalence and severity of back pain in Europe have examined the difference between women and men. In a study in Sweden, the pointprevalence of SF-36 bodily pain severity was reported to be $24 \%$ in women and $21 \%$ in men. Ihlebaek et al tested for gender differences in the lifetime, 1 year, and point prevalence of low back pain among working persons in two neighbouring regions of Norway and Sweden. The prevalence of low back pain was higher in females than in males in both regions during the entire study period. However, the lifetime prevalence of low back pain among men living in the Norwegian region was higher than that of women (Ihlebæk et al., 2006).

We have found in our study that females are under 2 times more risk than males in terms of having had bodily pain.

Women in our study were found to be nearly under 2 times more risk than men in terms of having worse vitality scores. SG Kornstein et al found in their study that women have significantly lower scores in terms of the area of vitality (Kornstein et al., 2000).

Most studies mention that women suffering from physical problems more than men. In our study, we found that women are under 2 times more risk than man in terms of having physical problems. This can be explained with females having a greater frequency of musculoskeletal pain than males, as concluded by Rollman and Lautenbacher (Rollman \& Lautenbacher, 2001).

People with any chronic diseases influences feel pain 2.3 times more than people with no chronic diseases. It is mentioned that there are few studies on HS and HRQOL (Van Son et al., 2013). Most of the studies interest with Health Quality of life and health status focused on separate chronic health condition. In a study which has been made with similar methodology in Turkey, participants who have chronic disease had significantly lower scores than participants who haven't chronic disease. Our study reports similar results (Canbaz, Sünter, Dabak, \& Pekşen, 2003).

People who have never married have significantly lower scores according to the variables of SF36, apart from mental health. 30 years ago, Gove introduced the theory of gender-related mental illness, which links women's psychological distress to their role in society. The main point of the theory is that marriage is not beneficial for women while it is emotionally beneficial for men (Simon, 2002). In a multilevel analysis by marital status, it was reported that single men had substantially worse QOL (both EQ-VAS and EQ-5D) than married men. However, according to EQ-VAS, the observed QOL values were higher in unmarried women than in married or divorced women. When assessed using EQ-5D, the QOL scores of single or divorced women were lower than married women (Han, Park, Kim, Kim, \& Park, 2014).

Our results support the hypothesis of Gove. We found that single people are approximately under 3 times more risk of having worse social functions and under 2 times more risk of having emotional problems.

The BMI and education level found as factors which influence the quality of life to be Gender, health status, marital status and age.

\section{Limitations and Strength}

Our work has some limitations. Perhaps, most important of these limitations in our work is the low number of women participant. The reason of this, we tried to meet people outside their homes instead of visiting them in their homes. Therefore, women could not be reached due to cultural reasons. Another limitation is our sample size. Our study population represented $3 \%$ of the total. 


\section{CONCLUSION AND RECOMMENDATION}

In our study, women living in Silivri district were found to be riskier for physical pain, physical problems, physical functions, social functions, emotional problems than men. We have found in our study that women are under 2 times more risk than men in terms of having experienced bodily pain. Age, gender and

\section{References}

Barros, M. B. d. A., César, C. L. G., Carandina, L., \& Torre, G. D. (2006). Desigualdades sociais na prevalência de doenças crônicas no Brasil, PNAD-2003. Ciência \& Saúde Coletiva, 11, 911-926.

Blyth, F. M., March, L. M., Brnabic, A. J., Jorm, L. R., Williamson, M., \& Cousins, M. J. (2001). Chronic pain in Australia: A prevalence study. Pain, 89(2-3), 127-134.

Bouhassira, D., Lantéri-Minet, M., Attal, N., Laurent, B., \& Touboul, C. (2008). Prevalence of chronic pain with neuropathic characteristics in the general population. Pain, 136(3), 380-387.

Brown, N., Melville, M., Gray, D., Young, T., Skene, A. M., \& Hampton, J. R. (2000). Comparison of the SF-36 health survey questionnaire with the Nottingham Health Profile in long-term survivors of a myocardial infarction. Journal of Public Health, 22(2), 167-175.

Canbaz, S., Sünter, A. T., Dabak, S., \& Pekşen, Y. (2003). The prevalence of chronic diseases and quality of life in elderly people in Samsun. Turkish Journal of Medical Sciences, 33(5), 335-340.

Curcani, M., \& Tan, M. (2011). The factors affecting the quality of life of patients who have undergone kidney transplants. Pakistan Journal of Medical Sciences, 27(5), 1092-1097.

Demiral, Y., Ergor, G., Unal, B., Semin, S., Akvardar, Y., Kıvırcık, B., \& Alptekin, K. (2006). Normative data and discriminative properties of short form 36 (SF-36) in Turkish urban population. BMC Public Health, 6(1), 247-255.

Fillingim, R. B., King, C. D., Ribeiro-Dasilva, M. C., RahimWilliams, B., \& Riley, J. L. (2009). Sex, gender, and pain: A review of recent clinical and experimental findings. The Journal of Pain, 10(5), 447-485.

Frank, L. D., Andresen, M. A., \& Schmid, T. L. (2004). Obesity relationships with community design, physical activity, and time spent in cars. American Journal of Preventive Medicine, 27(2), 87-96.

Han, K.T., Park, E. C., Kim, J. H., Kim, S. J., \& Park, S. (2014). Is marital status associated with quality of life? Health and Quality of Life Outcomes, 12(1), 109-119.

Ihlebæk, C., Hansson, T. H., Lærum, E., Brage, S., Eriksen, H. R., Holm, S. H. . . Indahl, A. (2006). Prevalence of low back pain and sickness absence: A "borderline"study in Norway and Sweden. Scandinavian Journal of Public Health, 34(5), 555-558.

Kirchengast, S., \& Haslinger, B. (2008). Gender differences in health-related quality of life among healthy aged and oldaged Austrians: Cross-sectional analysis. Gender Medicine, 5(3), 270-278. marital status seem to have greater influence on the variables of SF 36, even with the determined differences on the mean scores of SF 36 variables according to $\mathrm{BMI}$ and education level.

Acknowledgement: We would like to thank the Municipality of Silivri for their interest and assistance.

Kocyigit, H. (1999). Reliability and validity of the Turkish version of short form-36 (SF-36): A study in a group of patients will rheumatic diseases. Turk J Drugs Ther, 12, 102-106.

Kornstein, S. G., Schatzberg, A. F., Thase, M. E., Yonkers, K. A., McCullough, J. P., Keitner, G. I. . . Harrison, W. (2000). Gender differences in chronic major and double depression. Journal of Affective Disorders, 60(1), 1-11.

Kroenke, K., \& Spitzer, R. L. (1998). Gender differences in the reporting of physical and somatoform symptoms. Psychosomatic Medicine, 60(2), 150-155.

Lima, M. G., Barros, M. B. d. A., César, C. L. G., Goldbaum, M., Carandina, L., \& Ciconelli, R. M. (2009). Health related quality of life among the elderly: A population-based study using SF36 survey. Cadernos de Saúde Pública, 25(10), 2159-2167.

Mallmann, D. G., Galindo Neto, N. M., Sousa, J. d. C., \& Vasconcelos, E. M. R. d. (2015). Health education as the main alternative to promote the health of the elderly. Ciência $\&$ Saúde Coletiva, 20(6), 1763-1772.

Pappa, E., Kontodimopoulos, N., Papadopoulos, A. A., \& Niakas, D. (2009). Assessing the socio-economic and demographic impact on health-related quality of life: Evidence from Greece. International Journal of Public Health, 54(4), 241249.

Pinar, R. (2005). Reliability and construct validity of the SF-36 in Turkish cancer patients. Quality of Life Research, 14(1), 259264.

Ramos, L. R. (2003). Fatores determinantes do envelhecimento saudável em idosos residentes em centro urbano: Projeto Epidoso, São Paulo. Cadernos de Saúde Pública, 19, 793797.

Regitz-Zagrosek, V. (2012). Sex and gender differences in health: Science \& Society Series on Sex and Science. EMBO Reports, 13(7), 596-603.

Rollman, G. B., \& Lautenbacher, S. (2001). Sex differences in musculoskeletal pain. The Clinical Journal of Pain, 17(1), 2024.

Rustøen, T., Wahl, A. K., Hanestad, B. R., Lerdal, A., Paul, S., \& Miaskowski, C. (2004). Gender differences in chronic painfindings from a population-based study of Norwegian adults. Pain Management Nursing, 5(3), 105-117.

Simon, R. W. (2002). Revisiting the relationships among gender, marital status, and mental health. American Journal of Sociology, 107(4), 1065-1096.

Tajvar, M., Arab, M., \& Montazeri, A. (2008). Determinants of health-related quality of life in elderly in Tehran, Iran. BMC Public Health, 8(1), 323-331. 
Türkiye İstatistik Kurumu Başkanlığı. (2018a). Adrese dayalı nüfus kayıt sistemi. Retrieved from http://www.tuik.gov.tr/PreTablo. do?alt_id=1059

Türkiye İstatistik Kurumu Başkanlığı.(2018b). Adrese dayalı nüfus kayıt sistemi sonuçları, 2017. Retrieved from http://www.tuik. gov.tr/HbGetirHTML.do?id=27587

Türkiye İstatistik Kurumu Başkanlığı. (2018c). Nüfus projeksiyonları, 2018-2080. Retrieved from http://www.tuik. gov.tr/PreHaberBultenleri.do?id=30567

Van Son, M., De Vries, J., Roukema, J., \& Den Oudsten, B. (2013). Health status, health-related quality of life, and quality of life following ankle fractures: A systematic review. Injury, 44(11), 1391-1402.
Vlassoff, C. (2007). Gender differences in determinants and consequences of health and illness. Journal of Health, Population, and Nutrition, 25(1), 47-61.

Ware JE, K. M., \& Gandek, B. (2014). SF-36 Health survey manual $\&$ interpretation guide Lincoln, RI: Qualiymetric Incorporated.

Ware Jr, J. E., \& Sherbourne, C. D. (1992). The MOS 36-item short-form health survey (SF-36): I. Conceptual framework and item selection. Medical Care, 473-483.

World Health Organization (WHO). (2018). Health promotion. Retrieved from http://www.who.int/topics/health_ promotion/en/

Yakar, M. (2014). Türkiye'de ilçelere göre medyan yaş dağılımının mekânsal ve istatistiksel analizi. Electronic Turkish Studies, 9(11), 559-591. 
